\title{
AN ENVIRONMENTAL STUDY OF CASTING COPPER-CADMIUM ALLOYS
}

\author{
BY \\ E. KING \\ From the Department for Research in Industrial Medicine (Medical Research Council), London Hospital, E.I
}

(RECEIVED FOR PUBLICATION FEBRUARY 1, 1955)

An environmental study to measure the concentrations of airborne cadmium oxide was carried out at the factories referred to by Bonnell on page 181, reporting the results of the clinical investigation of men exposed to cadmium oxide fume. Bonnell found that a number of these men had symptoms of chronic cadmium poisoning. Although the working conditions in the industry have improved in recent years, it was considered that knowledge of the present exposure to cadmium fume would be of interest both in assessing the present risk to health, and in providing information which might be of value should further cases occur.

In both factories the cadmium oxide was produced during the manufacture of copper cadmium alloys. Pure cadmium is first alloyed with pure copper to give a master alloy containing 33 or $50 \%$ cadmium at factory $\mathrm{A}$, and $50 \%$ at factory $\mathrm{B}$. The final alloy contains 0.5 to $1 \%$ cadmium, from which wire or sheet is made.

In factory A, both stages of the alloy manufacture were carried out in one workshop, shown diagrammatically in Fig. 1. In factory B the alloys were made in separate workshops (Figs. 2 and 3). Details of the processes involved in each factory are given by Bonnell on page 183 .

\section{Equipment Used in the Survey}

A preliminary visit to the factories suggested that cadmium oxide was produced as a fume intermittently and was only part of the total airborne solid. At factory $\mathrm{A}$ the Rocker furnace was in continuous operation over a five-day week. At factory B the casting shop worked throughout a six-day week, while the special alloy shop was on day work only. The furnacemen, manhandling crucibles of molten

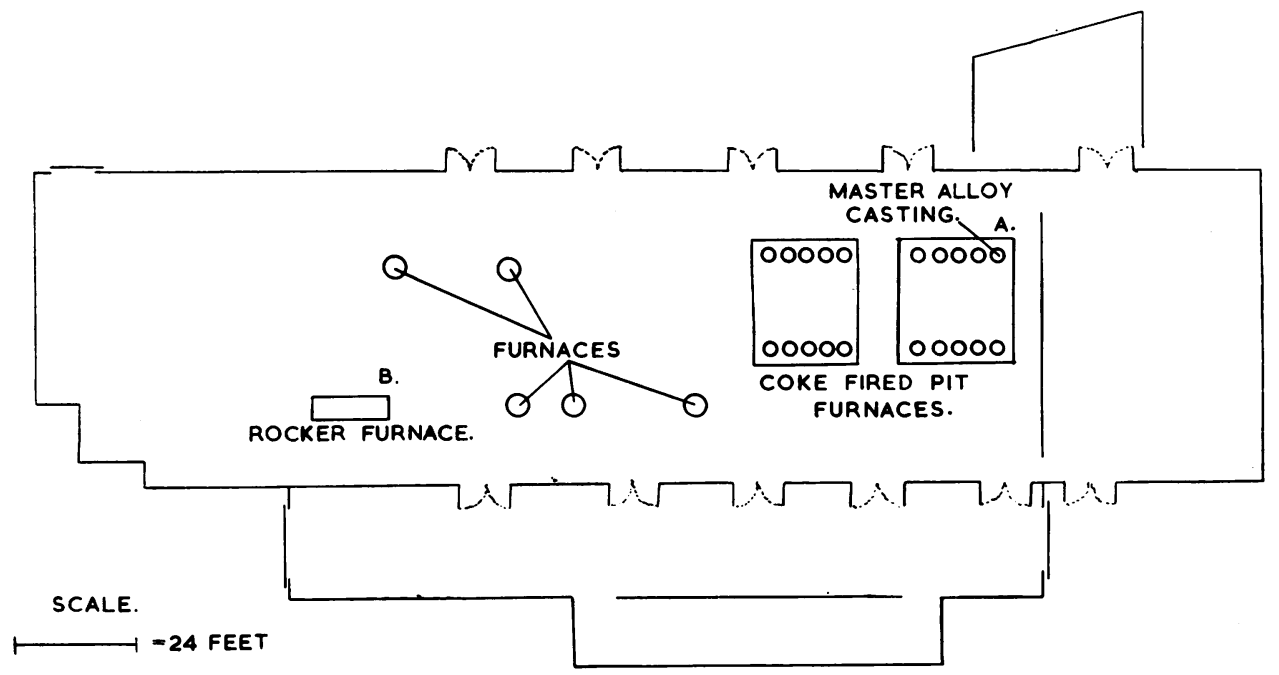

FIG. 1.-Diagram of cadmium alloy manufacture in factory A. 


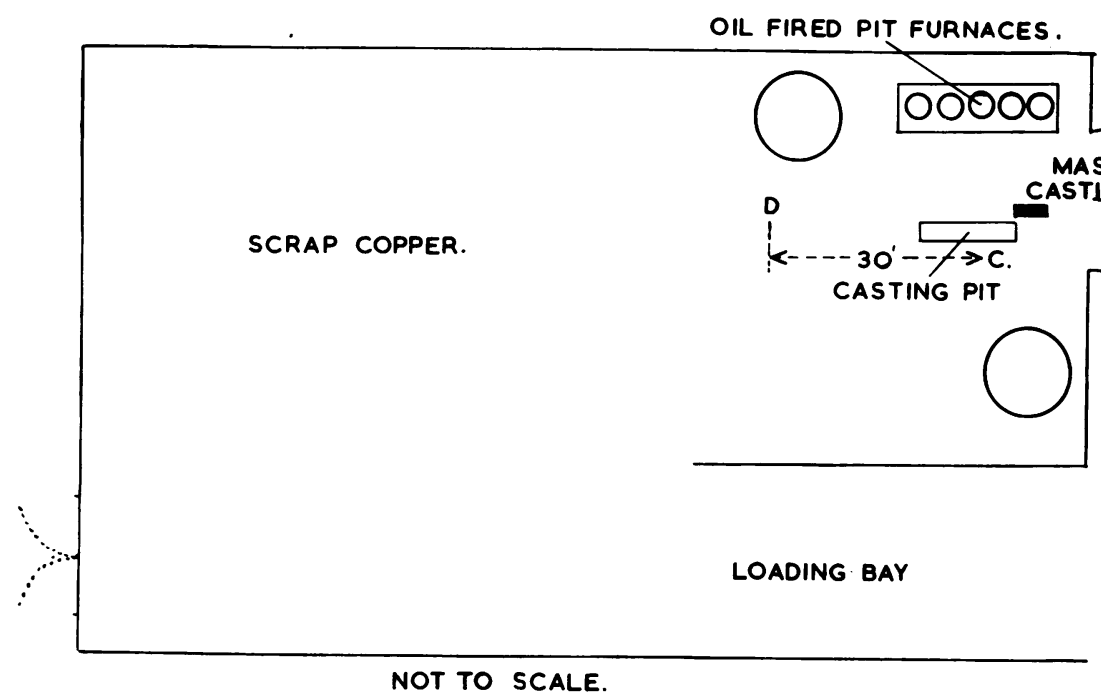

Fig. 2.-Diagram of master cadmium alloy manufacture in factory $B$.

metal, worked over an area of the workshops rather than in fixed positions.

The equipment used in the survey was chosen after consideration of the processes involved, and the conditions under which they were carried out. The requirement was for instruments to give mass concentrations, combined with particle size analysis, and to detect any unusually high concentrations which occurred during certain stages of the process.

Soluble Filter Pad.-The use of salicylic acid as a filtering material was reported by Briscoe, Matthews, Holt, and Sanderson in 1936. For this investigation, salicylic acid was unsuitable because it reacts chemically with cadmium oxide, and AnalaR dextrose was used in its place. The pads used were $1.5 \mathrm{~cm}$. thick, in a 3 in. diameter filter holder, with an air flow of 5 to $6 \mathrm{cu}$. ft. $/ \mathrm{min}$.

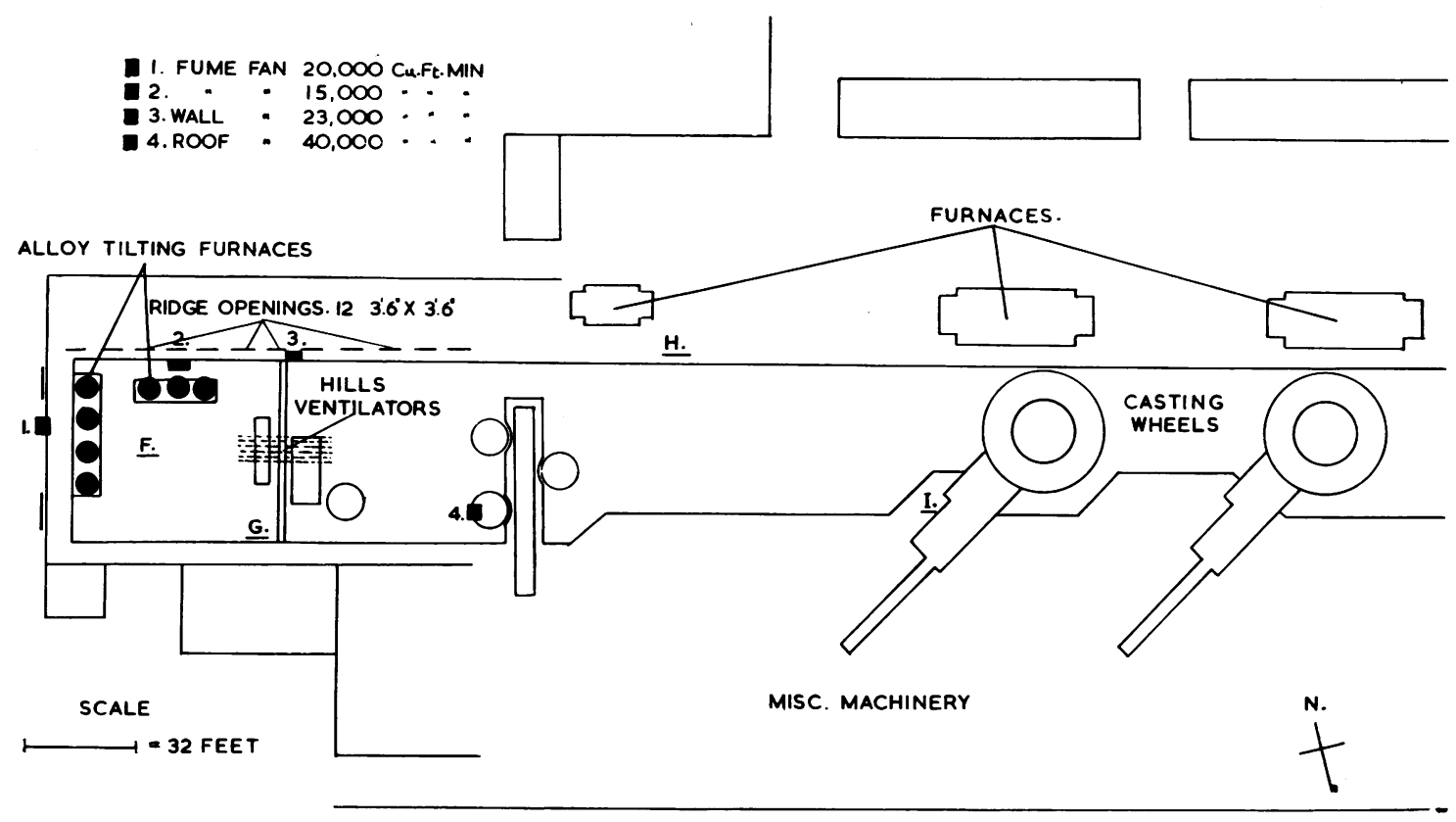

FIG. 3.-Diagram of final cadmium alloy manufacture in factory $\mathbf{B}$. 
measured by a gas meter. This equipment had been shown to give a high collecting efficiency, and could be left unattended for long periods under the conditions of low humidity found in the workshops.

In the laboratory the sample was dissolved in water and centrifuged to separate the solid fraction. A fraction of the supernatant dextrose solution was taken, and the cadmium content estimated. It was assumed that this represented the very fine particles which did not separate out either because of the viscosity of the solution or their partial solubility in neutral solution. The solid fraction was washed with water and alcohol, and a coarse separation into $>5 \mu$, from 5 to $0.5 \mu$, and $<0.5 \mu$ fractions carried out by triple sedimentation in alcohol. The cadmium found in the supernatant liquid was added to the $<0.5 \mu$ fraction. This procedure was used to give a semi-quantitative size distribution of the cadmium oxide.

The cadmium content of the samples was estimated on a polarograph at a half-wave potential of $-0.7 \mathrm{v}$, in $0.1 \mathrm{~N}$ ammonium chloride. The samples were found to contain copper in quantities sufficient to interfere with the cadmium wave, and a separation based on the solubility of cadmium sulphide in dilute hydrochloric acid $(33 \% \mathrm{v} / \mathrm{v})$ was carried out. The dry sample was dissolved in dilute hydrochloric acid $(33 \% \mathrm{v} / \mathrm{v})$ and the solution saturated with hydrogen sulphide. The copper sulphide was filtered off and washed with hydrochloric acid to dissolve any cadmium which had been precipitated with the copper.

The filtrate was heated to dryness and the residue dissolved in $0 \cdot 1 \mathrm{~N}$ ammonium chloride for cadmium analysis on a polarograph.

Confirmation of the analytical technique was obtained from a series of recovery experiments. These were based on the estimation of a known added amount of cadmium under the varying conditions occurring during the analysis. A total of 38 experiments reproducing parts of the technique, with cadmium chloride as the cadmium source, gave an average recovery of $91 \%$, with a standard deviation of 13 .

A final series of experiments was performed on samples representing as closely as possible the unknown samples. A known weight of cadmium oxide (0 to $10 \mathrm{mg}$.) was mixed with copper oxide ( 0 to $2 \mathrm{~g}$.) and dextrose (100 g.) for each of 13 samples. These were treated in the same way as the unknown samples, the only difference being that in the unknown samples the cadmium oxide was present as fume of very small particle size which did not separate from the dextrose solution, while in the prepared samples the cadmium oxide consisted of large particles and separated easily. Thus the bulk of the cadmium was found in different fractions in the two cases.

Of the 13 prepared samples, two gave anomalous results of 33 and $44 \%$ recovery. The remaining 11 gave a mean recovery of $81 \%$, with a range of 72 to $94 \%$. The anomalous results were probably caused by the nature of the cadmium oxide used. Polarographic analysis gave one low value of $66 \%$ in 10 weighed samples of cadmium oxide. The remaining nine gave an average purity of $98 \%$, with a range of 83 to $108 \%$.
The scatter observed throughout the recovery experiments was partly due to the polarograph used. To minimize this factor, the standard addition technique was adopted in all estimations, both in the recovery experiments and in the analysis of the samples.

Continuous Strip Recorder.-A continuous dust recorder based on the impingement of dust-laden air on to a celluloid strip is described by Hazard (1934), who used a photoelectric technique for estimating the dust on the resulting trace. The instrument used in this survey substitutes Whatman No. 1 strip filter paper for the celluloid moving across an orifice at 2 in. per hour, with air passing through the paper into the orifice at 41 ./min. The final record was used for visual observation, relating the intensity of the dust stain to times and processes, and for chemical analysis as required. The normal air pollution from furnace fuel and mould dressings gave a grey or black background marked with a brown coloration at each heavy emission of cadmium oxide.

Thermal Precipitator.-The thermal precipitator could not be used for quantitative measurements because of the high concentration of airborne dust other than cadmium oxide. In order to obtain a qualitative picture of the nature of the cadmium oxide emitted in the type of work involved, slides were taken near the Rocker furnace at factory $A$.

\section{Investigation at Factory A}

The workshop shown as Fig. 1 was engaged on general alloy production, including both master and final copper cadmium alloys. At one end of the workshop was a series of coke-fired pit furnaces, one of which (position A, Fig. 1) was used for the master copper cadmium alloy. At the centre of the workshop were a number of induction furnaces used for the production of alloys not containing cadmium. The Rocker furnace, used in the manufacture of the final cadmium copper alloy, was at position B, Fig. 1 .

The numerous doors shown in Fig. 1, when opened, provided good general ventilation inside the workshop.

The separation of the processes in this workshop was such that in the first instance only the areas around the two furnaces using cadmium were considered to be of interest. A detailed description of the nature and operation of the furnaces used in the cadmium processes is given by Bonnell (1955).

\section{Master Alloy}

The alloy made during the survey was $33 \%$ cadmium in copper in a coke-fired pit furnace at position $\mathrm{A}$ in Fig. 1. The cadmium was first melted in the crucible, copper added, and the mixture stirred manually. When the alloy was ready for pouring a lid was placed over the crucible, which 
was lifted from its pit, placed under an exhaust hood, and poured by mechanical means. The only fume emission observed occurred on removal of the crucible lid just before pouring.

The process was discontinuous, the master alloy being made in small batches as required by the Rocker furnace operation. Average values of 6, 5, 7, $\mu \mathrm{g}$. cadmium per cubic metre air were found over three days. These low values were due to the discontinuity of the process, and the dexterity of the furnaceman in using the exhaust hood. Under the conditions observed it is unlikely that significant concentrations of cadmium oxide would occur in the general working atmosphere.

\section{Final Alloy}

The final alloy made during the survey was a low cadmium-content alloy prepared from pure copper and master alloy in a Rocker furnace, at position B Fig. 1. The pure copper was first heated to melting point, taking 40 to 50 minutes, and the required amount of master alloy was added. The furnace was then rocked for five to 10 minutes, and the resulting alloy poured into an oil-dressed mould. From the time the master alloy was added to the end of pouring an exhaust hood, placed in position by the furnaceman, covered the centre and mouth of the furnace. Cadmium oxide fume was emitted, violently at first, and to a lesser degree up to the end of pouring. There was an obvious loss of fume from around the exhaust hood during pouring, and also some leakage from one end of the furnace.

The sampling equipment was placed $8 \mathrm{ft}$. from the furnace in such a position that the furnaceman was normally in the area between the equipment and the furnace, except during the rocking procedure, which he controlled from the far end of the furnace. The concentrations found thus represent a minimum rather than maximum exposure to cadmium oxide fume of persons working near the furnace.

The strip recorder gave a grey background trace, with black patches corresponding to the times when the Rocker or adjacent furnaces were pouring. In addition, peak emissions of cadmium oxide caused brown patches to show through the background.

The thermal precipitator was used at an earlier visit to the factory to take samples near the Rocker furnace at times of peak emission of fume. Photographs of three slides are shown (Figs. 4, 5, and 6).

The dextrose pad equipment was operating continuously over a five-day working week. The sample pad was changed at the end of each shift. Each furnaceman normally cast eight billets, of 51 cwt. each, per shift. On one shift, day 5 , shift 1
(Table 1), only one billet was cast because of the absence of the regular furnaceman.

The mass concentrations of cadmium, with the average size distribution, are given in Table 1.

TABLE 1

CADMIUM CONCENTRATIONS AT THE ROCKER FURNACE AT FACTORY A

\begin{tabular}{cc|c|c|c|c|c}
\hline & & \multicolumn{3}{|c}{ Concentrations $\left(\mu \mathrm{g}\right.$. Cd $/ \mathrm{m}^{3}$ Air $)$} \\
\cline { 3 - 7 } Shift & Time & Day 1 & Day 2 & Day 3 & Day 4 & Day 5 \\
\cline { 3 - 7 } & $06.00-14.00$ & 72 & 59 & 21 & 89 & 13 \\
2 & $14.00-22.00$ & 48 & 19 & 16 & 31 & 23 \\
3 & $22.00-06.00$ & 31 & 34 & 37 & 35 & 38 \\
\hline
\end{tabular}

Average size distribution $>5 \mu=4 \%$ by weight, $0 \cdot 5 \mu$ to $5 \mu=5 \%$ by weight, $<0.5 \mu=91 \%$ by weight.

\section{Results}

Throughout this paper the cadmium concentrations in the atmosphere have been given as average values, although in most cases the strip recorder showed that the nature of the work caused a comparatively high concentration for some 15 minutes of each hourly casting cycle. At other times there was insufficient cadmium present in the atmosphere to be seen through the black background caused by the burning oil. The mixing and casting operations gave rise to a dense yellow cloud of cadmium oxide fume at the mouth of the furnace or crucible which diffused and circulated according to local air movement. The exposure of the furnacemen at these times was entirely dependent on the care taken to avoid direct contact with the fume cloud, a very variable factor. Ideally, sampling equipment should have been used to monitor each furnaceman, but apart from the psychological effect on the men concerned, the conditions of working made this impossible.

Chemical analyses were performed on some of those sections of the strip records corresponding to the periods of peak emission, usually of about 15 minutes' duration. At factory A, position B, taking in both cases the average for four shifts, the concentrations at the peak times varied from 1.5 to 3 times the over-all concentrations. At factory $\mathrm{B}$, position $\mathrm{C}$, for one day, the average peak emission concentration was $450 \mu \mathrm{g}$. Cd/m. ${ }^{3}$, compared with an average of $132 \mu \mathrm{g} . \mathrm{Cd} / \mathrm{m}^{3}$ for the whole time. These concentrations were measured at positions some distance from the source of the cadmium oxide fume, and some diffusion of the fume cloud must have occurred before it was recorded.

\section{Investigation at Factory $B$}

Master Alloy.-The master alloy, containing 50\% cadmium, was made in the special alloys workshop, shown as Fig. 2. This workshop was used as a 


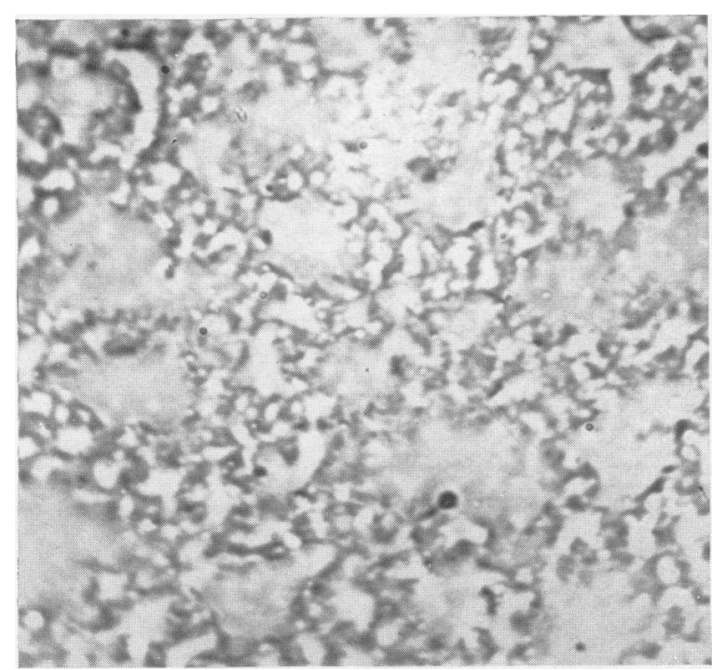

FIG. 4.

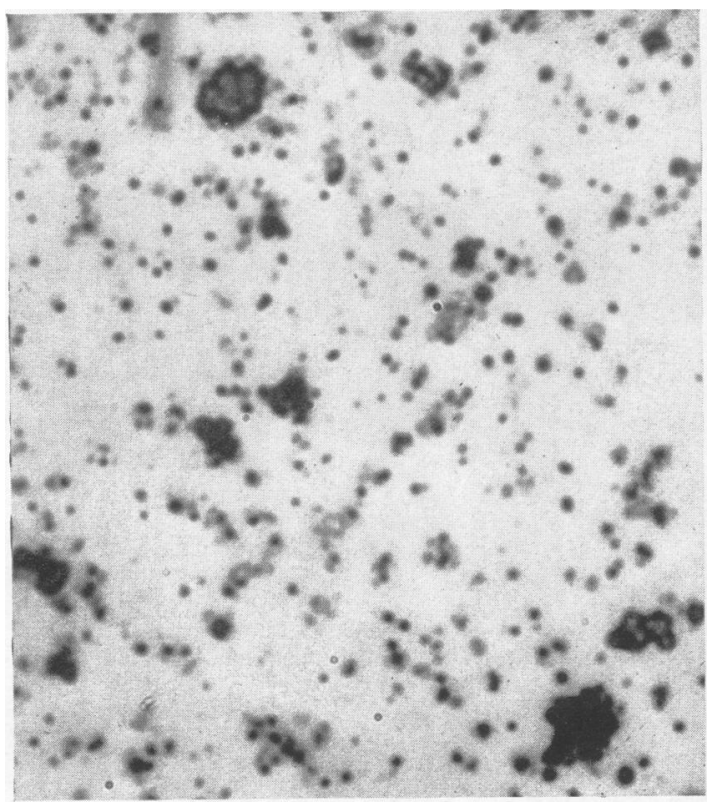

Fig. 5.

Fig. $4(\times 2,000)$. - Taken near the mouth of the furnace. This shows the fume nature of the cadmium oxide immediately on contact with the outside air.

Fig. $5(\times 2,000)$. - This was taken $3 \mathrm{ft}$. from the mouth of the furnace. This is probably the form in which the cadmium oxide usually occurs in the general atmosphere.

FIG. $6(\times 2,000)$. - This shows the cadmium oxide which was leaking from one end of the furnace. In this case the cadmium had travelled from the centre of the furnace, probably as metal fume, and had been oxidized at a lower temperature to give larger particles. general store for scrap copper, with associated handling equipment, except that it also contained a series of oil-fired pit furnaces and a brass recovery furnace. One of the pit furnaces was used for the master alloy, while the remainder made other alloys, including one of a lower cadmium content. The furnacemen were normally the only occupants of the workshop, and rarely moved away from the vicinity of the furnaces. They were on day work only.

The copper was first heated, and, when it was molten, the cadmium was added, a few sticks at a time. The mixture was stirred manually during this time. The crucible was finally lifted from its pit by an overhead crane and moved to the casting position, where it was tilted by hand and poured into a number of small moulds. Throughout the last stages of the process there was a continuous emission of cadmium oxide fume, the bulk of which was carried by convection to a small exhaust fan near the roof and discharged into the outer atmosphere. During the investigation the master alloy was made only on days 7, 8, and 9 (Table 2).

Sampling equipment was set up at position $\mathrm{C}$, Fig. 2, to measure the cadmium content of the atmosphere in the main working area, and at position $\mathrm{D}$ to obtain values at the perimeter of this area.

Oil dressings for the moulds used by the furnaces not making the master alloy caused a heavy background trace on the strip recorder. This background disappeared very quickly at the end of the working day, suggesting good ventilation of the workshop. At position $C$, brown patches showed through the

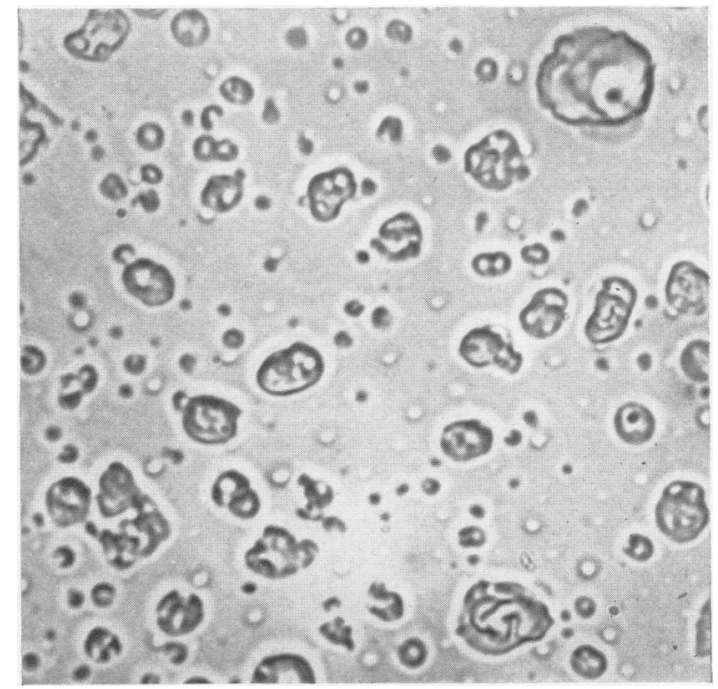

FIG. 6 
TABLE 2

CADMIUM CONCENTRATIONS AT MASTER ALLOY WORKSHOP AT FACTORY B

\begin{tabular}{|c|c|c|c|c|c|c|c|c|c|c|c|c|c|}
\hline \multirow{2}{*}{\multicolumn{2}{|c|}{ Position }} & \multicolumn{9}{|c|}{ Cadmium Concentrations ( $\mu \mathrm{g} . \mathrm{Cd} / \mathrm{m}^{3}$ Air) } & \multicolumn{3}{|c|}{$\%$ by Weight Average Size } \\
\hline & & Day 1 & Day 2 & Day 3 & Day 4 & Day 5 & Day 6 & Day 7 & Day 8 & Day 9 & $>5 \mu$ & $0 \cdot 5-5 \mu$ & $<0.5 \mu$ \\
\hline $\begin{array}{ll}\text { C } & \cdots \\
\text { D } & \cdots\end{array}$ & $\ldots$ & $\begin{array}{r}12 \\
4\end{array}$ & $\begin{array}{l}45 \\
34\end{array}$ & $\begin{array}{l}46 \\
11\end{array}$ & 二 & $\begin{array}{l}28 \\
11\end{array}$ & $\begin{array}{l}34 \\
10\end{array}$ & $\begin{array}{r}132 \\
55\end{array}$ & $\begin{array}{r}118 \\
69\end{array}$ & $\begin{array}{l}93 \\
77\end{array}$ & $\begin{array}{r}13 \\
5\end{array}$ & $\begin{array}{r}10 \\
6\end{array}$ & $\begin{array}{l}77 \\
89\end{array}$ \\
\hline
\end{tabular}

The master alloy was made on days $7,8,9$ only.

background corresponding to the times at which the alloy was made and cast. These patches did not occur on the strip recorder at position D, indicating that peak concentrations did not reach this point.

The results are summarized in Table 2.

The mass concentration figures showed the expected differences between positions $\mathrm{C}$ and $\mathrm{D}$ except on the final day. Because of the construction of the workshop, outside weather conditions could have resulted in a more general distribution of fume on that occasion.

Final Alloy.-Fig. 3 shows the lay-out of the workshop concerned in the manufacture of the final alloy at factory B. This workshop was largely concerned with processes in which no cadmium was used, from the refining of copper to the machining of the finished bars and billets. At one end of the workshop was a series of oil-fired tilting furnaces used for the final cadmium and other copper alloys. Each of the furnaces was covered by an exhaust hood which had to be partly displaced by the furnaceman during loading and mixing operations. In addition to the separate exhausts of these furnaces, this end of the workshop had general ventilation provided by the fans and openings shown in Fig. 3.

The copper was first heated to melting point in the crucible of the furnace, and the master alloy was then "tossed" in by the furnaceman. The mixture was stirred by hand with a pole, and the crucible tilted mechanically to cast the alloy into a mould below. During the latter processes, cadmium oxide fume could be seen escaping from under the exhaust hood and rising to roof level.

Sampling position F (Fig. 3) was 6 yards in front of the furnaces, and was the centre of the area used by the furnacemen except when operating the furnaces. The concentrations at this point therefore give average exposures, and do not include possible high intermittent exposures when mixing the alloy in the crucible. Sampling position $G$ was the extreme limit of movement of the furnacemen during normal operations. Equipment was installed at positions $\mathrm{H}$ and $\mathrm{I}$ to measure the concentrations in parts of the workshop remote from the source of cadmium oxide.

Contamination from the oil fuel and mould dressings caused a dense background on the strip recorder at all positions. Only at $F$ was any suggestion of the brown coloration caused by cadmium fume observed against this background.

The dextrose pad equipments were operated continuously over the sampling period, the pads being changed morning and evening. The concentrations found are given in Table 3.

The average concentrations at position $F$ showed two trends. In general the levels at night were higher than those of the corresponding day. This was probably due to the closing of doors and

TABLE 3

CADMIUM CONCENTRATIONS AT FINAL ALLOY PRODUCTION AT FACTORY B

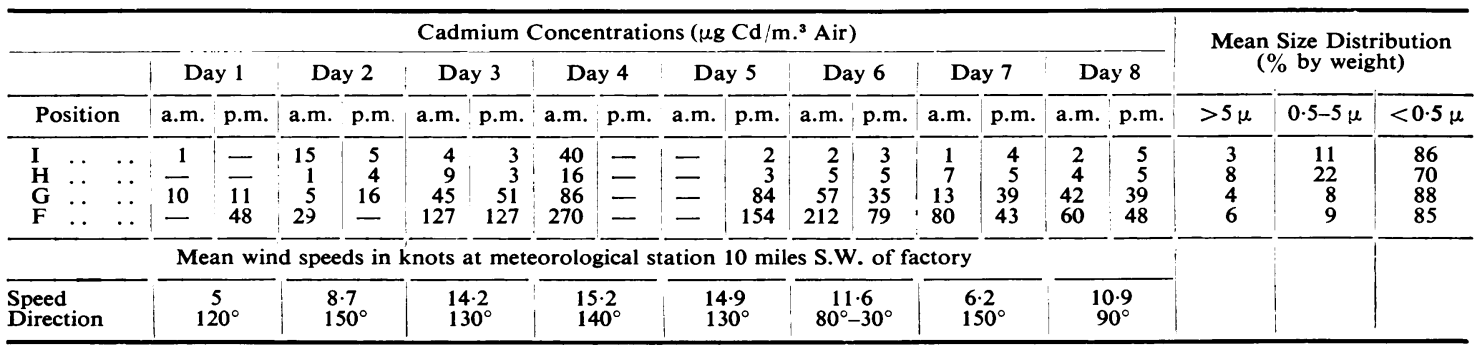

Sample at position $\mathrm{H}$ contaminated by sparks from nearby reverberatory furnace.

The workshop was closed for one 24 -hour period between days 4 and 5 .

a.m. $=10$ p.m. -10 a.m. (Day 4 to 6.30 a.m.)

p.m. = 10 a.m. -10 p.m. (Day 5 from 7.30 a.m.) 
consequent lack of natural ventilation at night. The second trend was a rise in concentrations on the middle days of the sampling period, and a subsequent fall later in the week which could not be correlated with the rate of working. The variations in wind speed obtained from a meteorological station 10 miles S.W. of the factory over this period suggest that weather conditions might affect ventilation of the workshop.

The mass concentrations at positions $\mathrm{H}$ and $\mathrm{I}$ suggest that there was no appreciable airborne cadmium oxide in those parts of the workshop distant from the cadmium operations.

\section{Discussion}

Friberg (1950) found a high incidence of chronic cadmium poisoning amongst workmen in factories manufacturing alkaline accumulators. The atmospheric concentrations of cadmium were found to be 3 to $15 \mathrm{mg}$. $/ \mathrm{m}$. ${ }^{3}$. Princi (1947) reported concentrations of 0.04 to $1.44 \mathrm{mg}$. Cd $/ \mathrm{m}^{3}$, with no cases of poisoning. Hardy and Skinner (1947) as a result of investigating a smaller group of men making cadmium-faced bearings, suggested that chronic cadmium poisoning might occur. They reported an average atmospheric concentration of $0.1 \mathrm{mg}$. Cd. $/ \mathrm{m}^{3}$. Friberg (1950) concludes from the evidence of these papers and his own findings that the maximum allowable atmospheric concentration of cadmium of $0.1 \mathrm{mg}$./ $\mathrm{m}^{3}{ }^{3}$, given by the American Conference of Governmental Industrial Hygienists (1954) should provide a satisfactory margin of safety.

The atmospheric concentrations found in factories $A$ and $B$ during this investigation cannot be strictly compared with those quoted above, because of differences in the nature of the cadmium and in general working conditions over the past years. The concentrations given in this paper relate to cadmium, as cadmium oxide, in the form of fume, which would be absorbed more rapidly and completely than the dust reported by Friberg (1950).

The present working conditions at factories $\mathrm{A}$ and B differ greatly from those of 1939-45, when " blackout" greatly reduced normal ventilation at night, and the chronic nature of the poisoning suggests that past conditions may be responsible for the present symptoms. In addition, since 1948 various improvements have been made in the ventilation of the processes used in these factories.

In factory $A$ the exhaust system over the furnace for the manufacture of the master alloy was introduced, and although no data are available for atmospheric concentrations before its introduction it can be assumed that the cadmium levels near the furnace were very much higher at that time.
The Rocker furnace has been in operation for about 19 years, originally without an exhaust hood. The concentrations at this point (position B, Fig. 1) arose from the manufacture of a low cadmiumcontent alloy. There appears to be a personal factor amongst the furnacemen, shift 1 giving higher levels than shift 2 . The more constant and lower levels of shift 3 at night, when the workshop doors were closed, suggest that in the absence of cross air currents, the exhaust system was sufficient to prevent a rising concentration of cadmium fume inside the workshop.

At factory B, the manufacture of the master alloy gave lower concentrations than would have been expected for a furnace not equipped with an exhaust hood. It could be seen that the convection effects of this type of furnace carried the cadmium oxide fume as a well-defined pillar to the exhaust fan near the roof. The natural ventilation from the nearby door dispersed residual fume, as shown on day 9 , Table 2, when the air movement was towards the remote end of the workshop. Under the conditions observed changes of wind could have caused wide variations in the cadmium oxide levels in the vicinity of the furnaces. This process had previously been carried out in a different workshop, and although no quantitative assessment was possible it was unlikely that a similar fortunate arrangement of ventilation applied.

The concentrations found during the manufacture of the master and final alloys at factory B were not proportional to the amount of cadmium used in the processes, and suggest that the percentage loss of cadmium to the air was greater in the manufacture of the final alloy. The three days, 7,8 , and 9 (Table 2), when the master alloy was produced supplied sufficient master alloy for several days' production of final alloy, and yet gave comparatively low concentrations in the atmosphere. This is also evident from Table 2, where the manufacture of a $7 \%$ alloy from master alloy and copper on days $2,3,5$, and 6 gave concentrations of about $30 \%$ of those due to the master $(50 \%)$ alloy. The probable explanation is the temperatures involved in the processes.

The variations in the concentrations found during this survey, together with the changes in working conditions that have taken place in recent years, make it impossible to relate concentrations of airborne cadmium to the incidence of cases of poisoning. Thus on the present evidence no definite conclusions regarding safe working conditions can be reached, but future routine atmospheric and medical examinations may provide sufficient information upon which to base recommendations. 


\section{Summary}

Mass concentration levels of cadmium as cadmium oxide fume in the atmosphere of the two factories making copper cadmium alloy are reported. Air samples were taken during five days at factory A and nine days at factory $B$.

The values at four of the positions represent the minimum concentrations to which the furnacemen operating the cadmium processes were exposed. Other values were obtained giving the exposure of vicinity workers.

The significance of these results is discussed.

I should like to thank the management of the two factories concerned, particularly the medical and per- sonnel departments, also Dr. Donald Hunter and Dr. D. G. Harvey for their encouragement and ready assistance. The polarographic estimations were carried out by Miss Jean Peal, and Messrs. Casbolt and Biles gave valuable technical assistance.

\section{REFERENCES}

American Conference of Governmental Hygienists, 16 th Annual Conference (1954), Arch. industr. Hyg. occupat. Med., 9, 530 . Conference (1954), Arch. industr. Hyg. occupat. Med., 9, 530.
Bonnell, J. A. (1955). British Journal of Industrial Medicine, 12, 181. Bonnell, J. A. (1955) British Journal of Industrial Medicine, 12, 181.
Briscoe, H. V. A., Matthews, J. W. Hoolt, P. F., and Sanderson,
P. M. (1936-37). Trans. I.M.M., 46, 145. P. M. (1936-37). Trans. I.M.M., 46, 145.
Friberg, L. (1950). Acta med. scand., Suppl. 240.

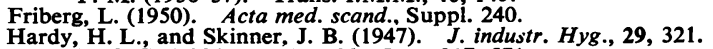
Hazard, W. G. (1934). J. Franklin Inst., 217, 571.

Princi, F. (1947). J. industr. Hyg., 29, 315. 